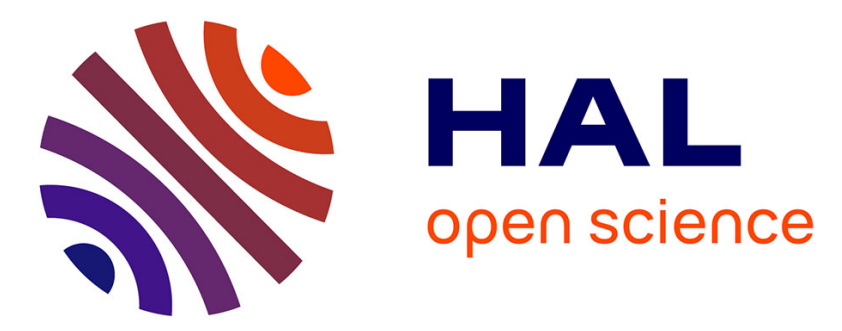

\title{
Effect of the microstructure and environmental exposure conditions on the corrosion behaviour of the 2050 alloy
}

Mathilde Guérin, Eric Andrieu, Grégory Odemer, Joël Alexis, Christine Blanc

\section{To cite this version:}

Mathilde Guérin, Eric Andrieu, Grégory Odemer, Joël Alexis, Christine Blanc. Effect of the microstructure and environmental exposure conditions on the corrosion behaviour of the 2050 alloy. Materials Science Forum, 2014, 794-796, pp.205-210. 10.4028/www.scientific.net/MSF.794-796.205 . hal-03217900

\section{HAL Id: hal-03217900 https://hal.science/hal-03217900}

Submitted on 5 May 2021

HAL is a multi-disciplinary open access archive for the deposit and dissemination of scientific research documents, whether they are published or not. The documents may come from teaching and research institutions in France or abroad, or from public or private research centers.
L'archive ouverte pluridisciplinaire HAL, est destinée au dépôt et à la diffusion de documents scientifiques de niveau recherche, publiés ou non, émanant des établissements d'enseignement et de recherche français ou étrangers, des laboratoires publics ou privés. 


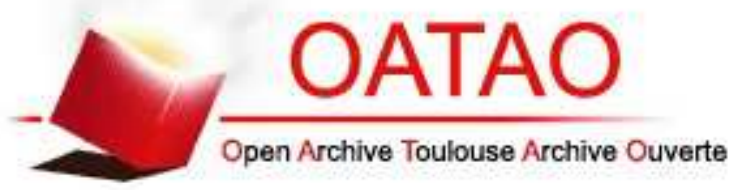

\section{Open Archive Toulouse Archive Ouverte (OATAO)}

OATAO is an open access repository that collects the work of Toulouse researchers and makes it freely available over the web where possible.

This is an author-deposited version published in: http://oatao.univ-toulouse.fr/ Eprints ID: 13670

To link to this article: DOI:10.4028/www.scientific.net/MSF.794-796.205 http://dx.doi.org/10.4028/www.scientific.net/MSF.794-796.205

\section{To cite this version:}

Guérin, Mathilde and Andrieu, Eric and Odemer, Grégory and Alexis, Joël and Blanc, Christine Effect of the microstructure and environmental exposure conditions on the corrosion behaviour of the 2050 alloy. (2014) Materials Science Forum, vol. 794-796. pp. 205-210. ISSN 0255-5476 


\title{
Effect of the microstructure and environmental exposure conditions on the corrosion behaviour of the 2050 alloy
}

\author{
Mathilde Guérin ${ }^{1, a^{*}}$, Eric Andrieu ${ }^{1, b}$, Grégory Odemer $^{1, c}$, Joël Alexis ${ }^{2, d}$ \\ and Christine Blanc ${ }^{1, e}$ \\ ${ }^{1}$ Université de Toulouse, Institut CARNOT CIRIMAT, UPS/CNRS/INPT, ENSIACET, \\ 4 allée Emile Monso, 31030 Toulouse Cedex 4, France \\ ${ }^{2}$ Université de Toulouse, LGP, ENIT/INPT, 47 Avenue d'Azereix, 65016 Tarbes, France \\ amathilde.guerin@ensiacet.fr, 'beric.andrieu@ensiacet.fr, 'ogregory.odemer@ensiacet.fr, \\ joel.alexis@enit.fr, ${ }^{e}$ christine.blanc@ensiacet.fr \\ ${ }^{*}$ corresponding author
}

Keywords: aluminium alloys, ageing, corrosion, immersion-emersion tests, grain boundaries.

\begin{abstract}
Alternate immersion-emersion tests were performed for a 2050 aluminium alloy to characterize its corrosion resistance with exposure conditions representative of in serviceconditions. Tests were performed for T34 samples and aged samples. After continuous immersion tests, T34 samples exhibited intergranular corrosion while intragranular corrosion was observed for aged samples. The alternate immersion-emersion tests led to a corrosion extension to the subgrain boundaries, for both T34 and aged samples, as shown by electron backscattered diffraction analysis.
\end{abstract}

\section{Introduction}

To reduce in weight aircraft metallic structures, new aluminium alloys are developed, e.g. the third generation aluminium-copper-lithium alloys [1]. Among these alloys, the Al-Cu-Li 2050 alloy is a very promising material but, depending on its metallurgical state, localized corrosion features (pitting, intragranular or intergranular corrosion) can be observed for this alloy due to its heterogeneous microstructure [2-3]. Al-Cu-Li alloys are precipitation-hardening alloys; the main strengthening phases can be $\mathrm{T}_{1}$ (of nominal composition $\mathrm{Al}_{2} \mathrm{CuLi}$ ) and those of the $\theta$ ' sequence (with its metastable precursors) $\left(\mathrm{Al}_{2} \mathrm{Cu}\right)$ [4]. Since the intermetallics do not have the same electrochemical reactivity as the matrix, galvanic coupling can occur at the microstructural scale leading to the localized corrosion morphology previously listed. Coarse intermetallic particles are mainly responsible for pitting [5-6]. The effect of the precipitation of finer intermetallics in Al-Cu$\mathrm{Li}$ alloys on their corrosion behaviour was also studied $[2,5,7-8]$. $\mathrm{T}_{1}$ precipitates were found to have a more negative corrosion potential than the matrix and were associated with dissolution phenomena such as intergranular corrosion [7-8]. It is worth noticing that most of the studies focused on the corrosion behaviour of $\mathrm{Al}-\mathrm{Cu}-\mathrm{Li}$ alloys are mainly related to continuous immersion tests, but throughout their life, aircraft structures are cyclically exposed to corrosive environment [9]. The aim of this work is to study the effect of exposure conditions to the aggressive media on the corrosion susceptibility of the 2050 alloy. To reproduce as closely as possible the environmental exposure conditions of the structural parts of an aircraft, cyclic corrosion tests with alternate immersion and emersion phases were conducted. Results were analyzed taking into account the microstructure of the alloy; to better understand the results, the 2050 alloy was studied in two metallurgical states, a T34 under peak aged state and a near peak aged state.

\section{Experimental}

Material. The material consisted of a 50-mm thick rolled plate of AA 2050 alloy (Al-3.5\% Cu$1 \% \mathrm{Li}$, weight percentage) provided by Constellium (France) in the T34 metallurgical state (solution 
treated, quenched, stretched and naturally aged). To study the influence of an ageing treatment on the corrosion behaviour of AA 2050 , T34 samples were aged at $155^{\circ} \mathrm{C}$ for 30 hours at a heating ramp of $20^{\circ} \mathrm{C} / \mathrm{h}$. In the following text, samples in the T34 metallurgical state and aged samples are referred to as NHT (non-heat treated) and HT (heat-treated), respectively. The grain structure revealed by Keller's etching corresponded to grains elongated in the longitudinal (L) direction, with, independently of the ageing treatment, average grain sizes larger than 500, 350 and equal to about $60 \mu \mathrm{m}$ in the L, long transverse (LT) and short transverse (ST) directions respectively.

Corrosion tests. All corrosion tests were performed in a $0.7 \mathrm{M} \mathrm{NaCl}$ solution on samples extracted from the core of the plate. The exposed area of each sample was $1 \mathrm{~cm}^{2}$. The ST-LT plane was exposed to the electrolyte in order to quantify the corrosion induced damage propagating in the L direction. Before corrosion tests, the samples were mechanically abraded up to 4000 grade, then polished with $3 \mu \mathrm{m}$ and $1 \mu \mathrm{m}$ diamond paste, rinsed in distilled water and air-dried. The temperature of both the laboratory room and the electrolyte was controlled and maintained at $22^{\circ} \mathrm{C}$. Three exposure conditions were studied. A cyclic corrosion test (CR test) consisted of three cycles of 24 hours; each cycle was composed of a 3 hours immersion in the electrolyte followed by a 5 hours dry period at the temperature of the laboratory room, then 2 hours immersion period and finally a 14 hours dry period. Two continuous immersion tests (CI tests) were considered as references. The first lasted 15 hours (CI 15h) which corresponded to the cumulated time of immersion for the cyclic corrosion tests and the second lasted 72 hours (CI 72h) which corresponded to the duration of the whole cyclic corrosion test. After the corrosion tests, each cubic sample was cut along the L-ST plane to obtain several slices; each slice was polished down to $1 \mu \mathrm{m}$ diamond paste and then observed using an optical microscope. To describe the corrosion morphology, two parameters were statistically determined: the number of corrosion defects propagating in the L direction and observed for a given distance in the ST direction (density of corrosion defects) and the average depth of corrosion defects in the L direction. Taking into account the cumulated length of corroded surface observed in the ST direction, i.e. $80 \mathrm{~mm}$, and the grain size in this direction (about $60 \mu \mathrm{m}$ ), almost 1000 grain boundaries and grains were observed for each test. A Scanning Electron Microscope (ZEISS EVO HD LS15; incident electron beam kept at $15 \mathrm{kV}$ ) was used to carefully examine corrosion defects. Each corrosion test was replicated 3 times.

Electron Backscattered Diffraction experiments. EBSD scans were performed on L-ST and LT-ST planes of the samples by means of a JEOL 7000F field emission gun SEM at an accelerating voltage of $15 \mathrm{kV}$ with a Nordlys II F+ camera. Before corrosion tests, measurements were carried out with a step size of $1 \mu \mathrm{m}$ for the $1000 * 2000 \mu \mathrm{m}^{2}$ maps. More precise maps were also obtained around corrosion defects with a step size of $0.5 \mu \mathrm{m}$. The orientation data were post-processed with the commercial orientation imaging software package Oxford Channel 5. The Inverse Pole Figure (IPF) maps represent the crystal orientation parallel to the sample surface normal.

\section{Results and discussion}

Corrosion behaviour of 2050 alloy during continuous immersion tests. After CI tests, NHT samples were found to be susceptible to intergranular corrosion (Fig. 1a and c); the corrosion defects depth in the L direction and their width in the ST direction increased when the duration of the corrosion test increased with corrosion defects propagating faster in the L direction. For HT samples, intragranular corrosion, characterized by the dissolution of the whole grain (Fig. 1b and d), was evidenced. When the immersion time increased, intragranular corrosion defects propagated both in the L and ST direction in agreement with the grain morphology. Results obtained concerning the corrosion morphology of NHT and HT samples were in good agreement with literature data obtained for another heat of 2050 alloy [8]. In this previous work [8], results showed that, for the NHT samples, $T_{1}$ precipitates were mainly localized at the grain boundaries. Dissolution of the 
grain boundaries was promoted due the more negative corrosion potential of $\mathrm{T}_{1}$ precipitates compared to that of the aluminium matrix. When the NHT samples were aged, the density and size of $\mathrm{T}_{1}$ precipitates in the grain boundaries increased but numerous $\mathrm{T}_{1}$ precipitates also formed inside the grains. Therefore, both the corrosion potentials of the grain boundaries and the grains became more negative with a decrease of the difference between the two corrosion potential values. The galvanic coupling effect between the grains and the grain boundaries was reduced so that intergranular corrosion did not occur. Moreover, with a more negative potential due to the presence of $\mathrm{T}_{1}$ precipitates and to a lower copper content, the grains in the HT samples were more reactive leading to intragranular corrosion. In the present study, transmission electron microscopy observations were performed for both NHT and HT samples. For HT samples, results were in agreement with literature data [8]; for NHT samples, no $T_{1}$ precipitates were observed at the grain boundaries. This suggested that the susceptibility to intergranular corrosion of 2050 alloy could be explained taking into account the presence of $\mathrm{T}_{1}$ precipitates at the grain boundaries but this was not mandatory. Intergranular corrosion could be also observed in the absence of $\mathrm{T}_{1}$ precipitates at the grain boundaries. In this case, the anodic behaviour of the grain boundaries could be attributed to the segregation of alloying elements. Further analyses are in progress to validate this hypothesis.

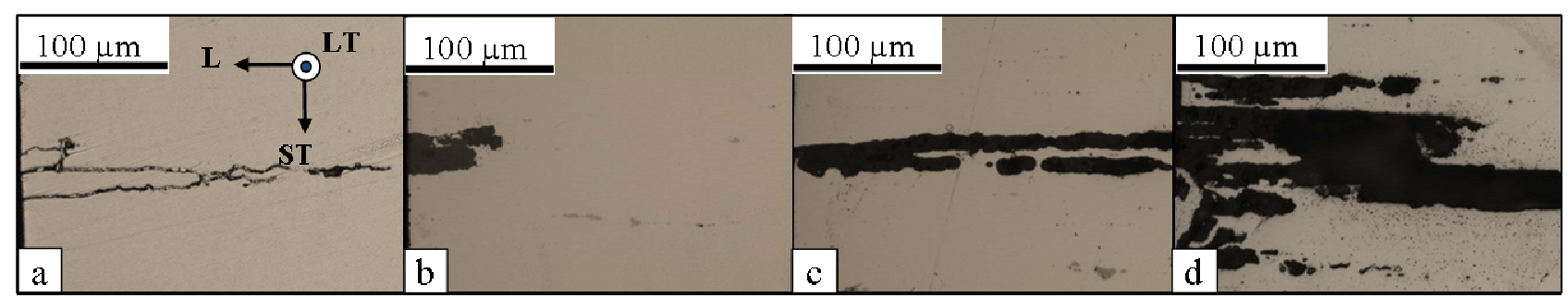

Figure 1. NHT a) and HT b) samples after CI 15h. NHT c) and HT d) samples after CI 72h.

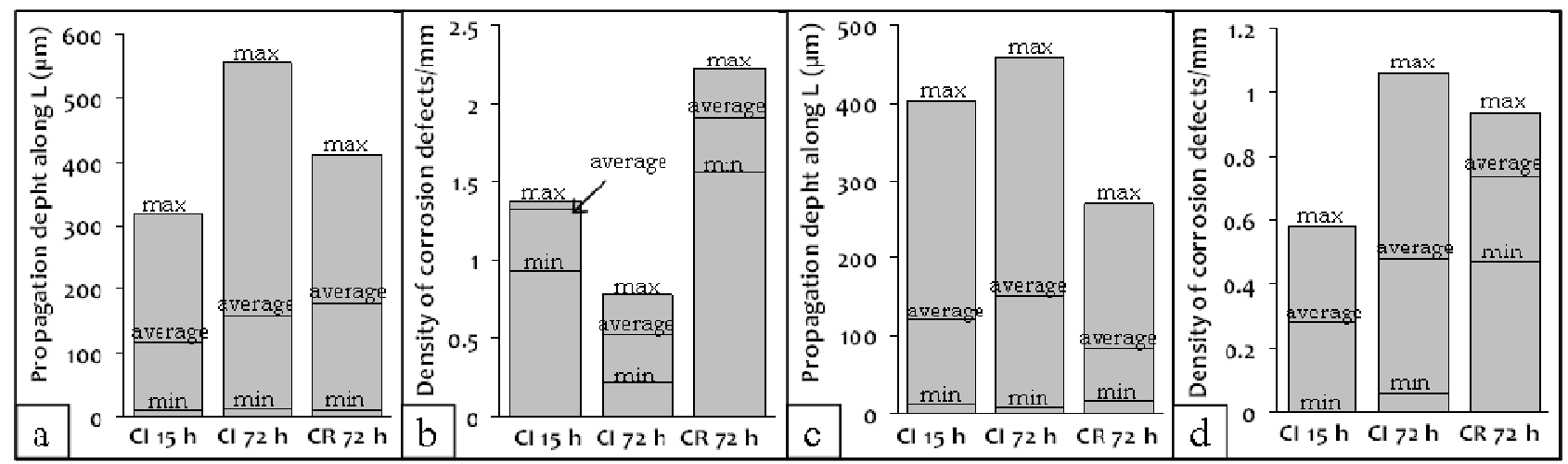

Figure 2. Propagation depth along L direction for a) NHT and c) HT samples. Density of corrosion defects in the ST direction for b) NHT and d) HT samples.

Fig. 2 shows the average, maximum and minimum values for the propagation depth in the $\mathrm{L}$ direction and the density of corrosion defects in the ST direction for both NHT and HT samples after CI tests. Because the distributions of the values were not normal, this representation was chosen for each set of data and the standard deviations were not given. For both samples, the results obtained for the average propagation depth of the corrosion defects were in good agreement with previous observations (Fig. 1). For NHT samples, the average propagation depth increased from 115 $\mu \mathrm{m}$ to $160 \mu \mathrm{m}$ after CI $15 \mathrm{~h}$ and CI $72 \mathrm{~h}$ respectively. For HT samples, similar values were obtained for the average propagation depth. Concerning the density of corrosion defects, it surprisingly decreased when the immersion time increased for NHT samples while it was logically found to increase for HT samples. These results evidenced that the characterization of the morphology of corrosion defects by using optical observation of the corroded surface is very difficult as shown by a previous study performed on a 2024 alloy [10]. Even though more than 1000 grain boundaries were observed for each sample, it was probably not enough to take into account the large distribution of 
the corrosion defect depths and the heterogeneous distribution of the corrosion defects on the sample surface. Therefore, it was assumed that the errors on the previous corrosion depths could be significant. Additional tensile tests were therefore performed on pre-corroded NHT and HT samples to validate the corrosion depth measurements [10]. Results showed that the corrosion depth values obtained for both NHT and HT samples after continuous immersion tests were relevant.

Corrosion behaviour of 2050 alloy during cyclic corrosion tests. Optical micrographs of NHT and HT samples show that a CR test (Fig. 3) leads to an evolution of the corrosion morphology compared to CI tests (Fig. 1). After a CR test, intergranular corrosion was still observed for NHT samples but the corrosion defects were thinner (in the ST direction) and more branched (Fig. 3a). Fig. 2 shows that their average depth in the L direction was higher; after a CR test, it was equal to $180 \mu \mathrm{m}$, for a total immersion time of 15 hours, while, after CI $15 \mathrm{~h}$ and CI 72h, it was equal to 115 and $160 \mu \mathrm{m}$ respectively. The density of corroded grain boundaries was increased with cyclic corrosion tests. Fig. 3c suggested that the branching could be attributed to both an extent of the corrosion to a larger number of grain boundaries but also to the dissolution of subgrain boundaries. For HT samples, Fig. $3 \mathrm{~b}$ and d show that intragranular corrosion was still observed after CR tests but intergranular corrosion and/or corrosion of subgrain boundaries were also observed. Fig. 2 shows that the average depth of the corrosion defects in the L direction was lower after CR tests by comparison with CI tests while the density of the corrosion defects was significantly increased.

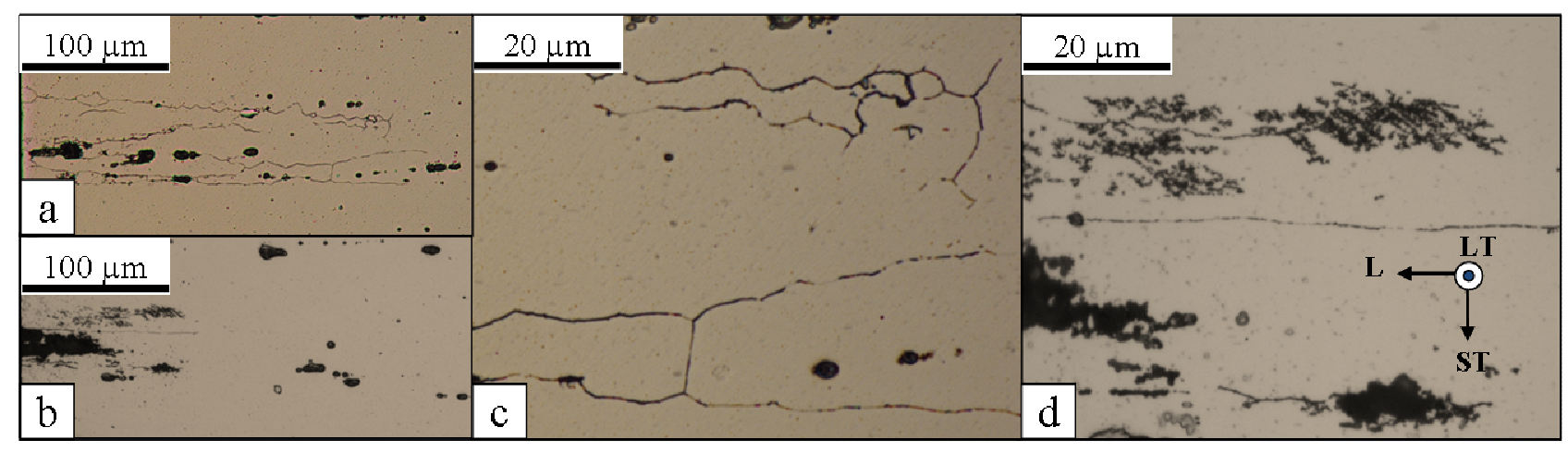

Figure 3. Optical micrographs of 2050 alloy samples after cyclic corrosion tests. a) NHT sample b) HT sample. Zoom on corrosion defects for c) NHT and d) HT samples.
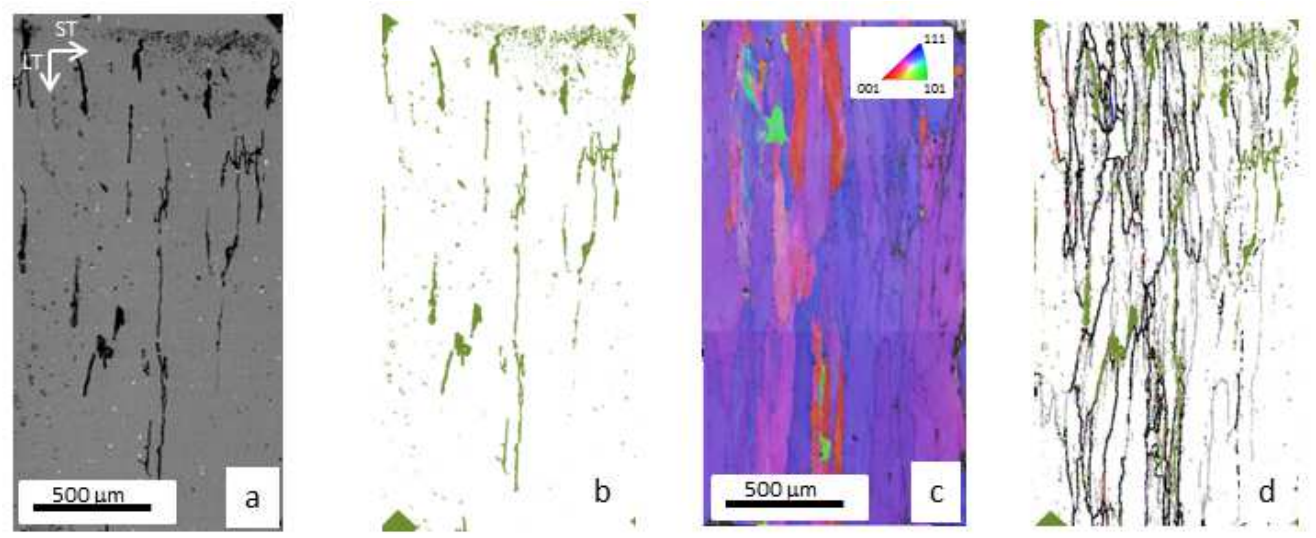

Figure 4. Analysis of a NHT sample after a CI test in a well-identified zone. a) SEM observation of the corrosion defect, backscattered electron image b) 'corrosion map' c) IPF-z0 d) identification of the interfaces (grain boundaries in black or in colour and subgrain boundaries in grey)

To better characterize the evolution of the corrosion defect morphology after CR tests, EBSD experiments were performed on both CI and CR samples. Fig. 4 illustrates the methodology used. In a first step, several zones were accurately localized. For each zone, IPF-z0 were plotted to reveal the 
grain and subgrains (Fig. 4c) and the misorientations were calculated to differentiate grain boundaries and subgrain boundaries. Interfaces are considered as grain boundaries for misorientations higher than $10^{\circ}$ and subgrain boundaries for misorientations from 2 to $10^{\circ}$. Then, the sample was slightly polished, submitted to the corrosion test, rinsed and dried. All the zones previously localized were observed using a SEM in the backscattered electron mode (Fig. 4a) to easily evidence the corrosion defects due to the presence of corrosion products. SEM micrographs were then analyzed using an Image analysis software (Image J) and the corrosion defects were highlighted (Fig. 4b) to obtain a 'corrosion map'. This map was superimposed on the IPF-z0 (Fig. $4 \mathrm{c}$ and d) to determine the nature of the corroded 'object' (interface or grain) and of the corroded interface (grain boundaries or subgrain boundaries). This methodology was applied for NHT and HT samples after CI and CR tests. Results showed that, after CI tests, corrosion defects were localized at the grain boundaries for NHT samples while, for HT samples, corrosion propagated inside the grains in good agreement with observations shown in Fig. 1. EBSD analysis confirmed that cyclic corrosion tests led to a modification of the corrosion morphology by comparison to continuous immersion tests. After CR tests, for NHT samples, corrosion extended to the subgrain boundaries (Fig. 5a, b and c). For HT samples, intragranular corrosion was still observed but a few grain boundaries and a large amount of subgrain boundaries were found to be corroded (Fig. $5 \mathrm{~d}$, e and f). For NHT samples, the extension of the corrosion to the subgrain boundaries leading to more branched corrosion defects could be explained by taking into account the evolution during the emersion period of the chemical composition of the electrolyte trapped inside the corrosion defects. Partial drying of the corrosion products led to an increase of the chloride concentration inside the corrosion defects. The electrolyte became more aggressive allowing the dissolution of the subgrain boundaries and promoting the propagation of the corrosion defects which were found to be deeper (Fig. 2). For HT samples, the increase of the aggressiveness of the electrolyte trapped inside the corrosion defects also led to the corrosion of the subgrain boundaries and even of some grain boundaries so that both intragranular and 'intergranular' corrosion were observed. The corrosion of the grains was also promoted but in the ST direction so that, after CR tests, the average depth of the corrosion defects in the L direction was lower compared to CI tests (Fig. 2).
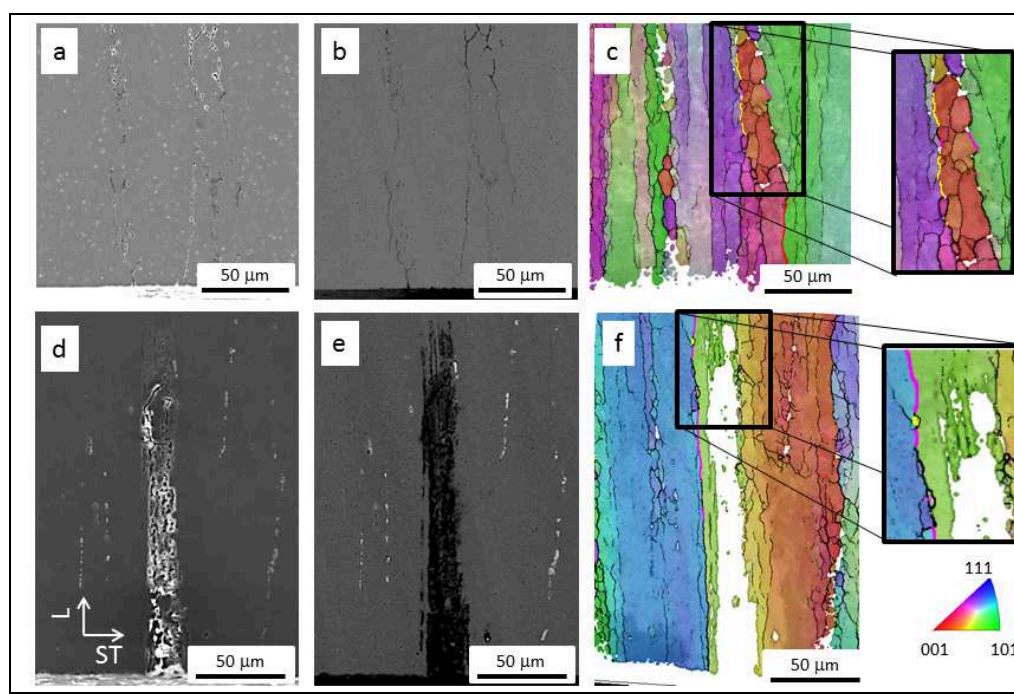

Figure 5. SEM observations of a), b) NHT and d), e) HT samples after CR tests. a) and d) are secondary electron images and b) and e) are electron backscattered images. Superimposition of IPF-zo, identification of the interfaces and 'corrosion map' for c) NHT and f) HT samples

Additional tensile tests were performed for corroded samples after CR tests and confirmed that $\mathrm{CR}$ tests were more damaging than CI tests leading to a greater decrease of the mechanical properties compared to CI tests. For NHT samples, this was in good agreement with an increase of the corrosion defects density and depth and the extension of the corrosion to the subgrain boundaries. For HT samples, this could be explained also by the extension of the corrosion to the subgrain boundaries; however, the decrease of the mechanical properties was significant by comparison to CI tests and this seemed surprising taking into account the depth of the corrosion 
defects. Hydrogen content of the corroded samples was measured and preliminary results seemed to show a hydrogen enrichment for both NHT and HT samples after CR tests which could explain the strong decrease of the mechanical properties and could be linked to the extension of the corrosion to the subgrain boundaries. This result could be compared to those obtained for 2024 alloy [9]. Additional experiments are in progress to confirm this assumption.

\section{Conclusions}

The 2050 aluminium alloy is susceptible to intergranular corrosion or intragranular corrosion depending on its metallurgical state, and mainly on the distribution of $\mathrm{T}_{1}$ precipitates; but segregation of alloying elements has also to be taken into account. The exposure conditions to the aggressive environment are another first order parameter. Alternate immersion-emersion tests can generate an extension of the corrosion to the subgrain boundaries even for a metallurgical state that generates only intragranular corrosion during continuous immersion tests.

\section{Acknowledgment}

The Région Midi-Pyrénées financially supported this work. The authors thank Dr J. Delfosse (EADS IW, France) and Dr C. Henon (Constellium, France) for fruitful discussions.

\section{References}

[1] R. J. Rioja, J. Liu, Evolution of Al-Li base products for aerospace and space applications, Metall. Mater. Trans. A 43A (2012) 3325-3337.

[2] J.E Kertz, P.I Gouma, R.G. Buchheit, Localized Corrosion Susceptibility of Al-Li-Cu-Mg-Zn Alloy AF/C458 due to Interrupted Quenching from Solutionizing Temperatures, Metall. and Mater. Trans. A 33 (2001) 2561-2573.

[3] N. Jiang, J. F. Li, Z. Q. Zheng, Effect of aging on mechanical properties and localized corrosion behaviors of Al-Cu-Li alloy, Transactions of non ferrous metals society of China 15 (2005) 23-29.

[4] B. Decreus, A. Deschamps, F. De Geuser, P. Donnadieu, C. Sigli, M. Weyland, The influence of $\mathrm{Cu} / \mathrm{Li}$ ratio on precipitation in $\mathrm{Al}-\mathrm{Cu}-\mathrm{Li}-\mathrm{x}$ alloys, Acta Mater. 61 (2013) 2207-2218.

[5] R.G. Buchheit, J.P. Moran, G.E. Stoner, Localized corrosion behavior of alloy 2090-the role of microstructure heterogeneity, Corrosion 46 (1990) 610-617.

[6] F. Viejo, A.E. Coy, F.J. Garcia, Z. Liu, P. Skeldon, G.E. Thompson, Relationship between microstructure and corrosion performance of AA2050-T8 aluminium alloy after excimer laser surface melting, Corros. Sci. 52 (2010) 2179-2187.

[7] C. Henon, S. Rouault, Comparison of corrosion performance and mechanisms of Al-Cu alloys with and without Li addition, Proceeding of the 13th International Conference on aluminium alloys, TMS, Pittsburgh, USA, 2012.

[8] V. Proton, J. Alexis, E. Andrieu, J. Delfosse, A. Deschamps, F. De Geuser, M.-C. Lafont, C. Blanc, The influence of artificial ageing on the corrosion behaviour of a 2050 aluminium-copperlithium alloy, Corros. Sci. 80 (2014) 494-502.

[9] C. Larignon, J. Alexis, E. Andrieu, C. Blanc, G. Odemer, J.-C. Salabura, Corrosion Damages Induced by Cyclic Exposure of 2024 Aluminum Alloy in Chloride-Containing Environments, J. Electrochem. Soc. 58 (2011) C284-C295.

[10] C. Augustin, E. Andrieu, C. Blanc, J. Delfosse, G. Odemer, Empirical Propagation Laws of Intergranular Corrosion Defects Affecting 2024 T351 Alloy in Chloride Solutions, J. Electrochem. Soc. 157 (2010) C428-436. 


\section{Aluminium Alloys 2014 - ICAA14}

10.4028/www.scientific.net/MSF.794-796

\section{Effect of the Microstructure and Environmental Exposure Conditions on the Corrosion Behaviour of the 2050 Alloy}

10.4028/www.scientific.net/MSF.794-796.205

\section{DOI References}

[2] J. E Kertz, P. I Gouma, R.G. Buchheit, Localized Corrosion Susceptibility of Al-Li-Cu-Mg-Zn Alloy AF/C458 due to Interrupted Quenching from Solutionizing Temperatures, Metall. and Mater. Trans. A 33 (2001) 2561-2573.

http://dx.doi.org/10.1007/s11661-001-0046-5

[4] B. Decreus, A. Deschamps, F. De Geuser, P. Donnadieu, C. Sigli, M. Weyland, The influence of Cu/Li ratio on precipitation in Al-Cu-Li-x alloys, Acta Mater. 61 (2013) 2207-2218.

http://dx.doi.org/10.1016/j.actamat.2012.12.041

[5] R.G. Buchheit, J.P. Moran, G.E. Stoner, Localized corrosion behavior of alloy 2090-the role of microstructure heterogeneity, Corrosion 46 (1990) 610-617.

http://dx.doi.org/10.5006/1.3585156

[6] F. Viejo, A.E. Coy, F.J. Garcia, Z. Liu, P. Skeldon, G.E. Thompson, Relationship between microstructure and corrosion performance of AA2050-T8 aluminium alloy after excimer laser surface melting, Corros. Sci. 52 (2010) 2179-2187.

http://dx.doi.org/10.1016/j.corsci.2010.03.003

[8] V. Proton, J. Alexis, E. Andrieu, J. Delfosse, A. Deschamps, F. De Geuser, M. -C. Lafont, C. Blanc, The influence of artificial ageing on the corrosion behaviour of a 2050 aluminium-copperlithium alloy, Corros. Sci. 80 (2014) 494-502.

http://dx.doi.org/10.1016/j.corsci.2013.11.060 